\title{
Age-group differences in risk perceptions of non-communicable diseases among adults in Diepsloot township, Johannesburg, South Africa: A cross-sectional study based on the Health Belief Model
}

\author{
Z Kaba, ${ }^{1}$ BPH; N Khamisa, ${ }^{1} \mathrm{PhD}$; N Tshuma, ${ }^{1,2} \mathrm{BSc}, \mathrm{MBA}$ \\ ${ }^{1}$ Department of Public Health, School of Health Sciences, Monash South Africa, Johannesburg, South Africa \\ ${ }^{2}$ Community AIDS Response, Johannesburg, South Africa
}

Corresponding author: Z Kaba (kaba.zahra@gmail.com)

Background. Non-communicable diseases (NCDs) in South Africa (SA) occur simultaneously with an ageing HIV-positive population, resulting in premature deaths in persons $<70$ years of age. Poor risk perception of NCDs results in poor adoption practices of NCD preventive measures. There is a gap in age-related research regarding risk perceptions of NCDs among the SA population.

Objective. To investigate age-group differences in risk perceptions of NCDs based on the Health Belief Model.

Methods. This cross-sectional design used secondary data obtained from Community AIDS Response (CARe), Johannesburg, SA. Data were collected by means of a cross-sectional survey in Extension 2 (Blocks I, J, K and L) of Diepsloot township, Johannesburg, SA. The Pearson $\chi^{2}$ test of independence was used to examine the relationship between age groups and risk perceptions of NCDs. A $p<0.05$ value was considered statistically significant.

Results. A total of 2135 participants were included in the analysis, of whom $71.5 \%$ were young adults (18 - 35 years). The mean age of the study participants was 32.1 (standard deviation 9.87) years. Significant associations were found between age groups and risk perceptions of NCDs. More middle-aged adults than young adults and older-aged adults perceived family history $(74.00 \% \mathrm{v} .72 .74 \% \mathrm{v} .62 .39 \%, p=0.045)$ and smoking $(83.80 \%$ v. $77.20 \%$ v. $74.31 \%, p=0.004)$ as risk factors that would increase their risk of NCDs. A higher proportion of older-aged adults than young adults and middle-aged adults perceived effects on life and family ( $89.91 \% \mathrm{v} .77 .39 \% \mathrm{v} .75 .40 \%, p=0.004)$ as risks of NCD morbidities. More middle-aged adults than young adults and older-aged adults perceived the usefulness of not smoking (84.60\% v. $81.06 \%$ v. $74.31 \%, p=0.028$ ) as an effective NCD preventive measure. More young adults than middle-aged and older-aged adults considered health check-ups (59.31\% v. $58.00 \%$ v. $41.28 \%, p=0.001)$ as a time-consuming process to prevent risks of NCDs.

Conclusion. Young adults had poorer risk perceptions of NCDs than middle-aged and older-aged adults in Diepsloot township, resulting in poor practice of NCD preventive measures among young adults in the area. This may be due to the misunderstanding of the concept of invulnerability, possibly resulting from the limited access and exposure to NCD-related information among young adults compared with middle-aged and older-aged groups. This highlights the need to expand public health education programmes to increase outreach to the young adult population and increase accessibility to information relating to NCD risks, and encourage adoption of NCD preventive measures.

S Afr Med J 2017;107(9):797-804. DOI:10.7196/SAMJ.2017.v107i9.12168

Non-communicable diseases (NCDs) continue to be the leading cause of avoidable disability worldwide. ${ }^{[1]}$ According to the World Health Organization (WHO), NCDs have resulted in 38 million deaths globally in 2010 - 2012, with low- and middle-income countries accounting for 28 million deaths. ${ }^{[2-4]}$ South Africa (SA) was one of the 23 countries that largely contributed to the 28 million NCD-related disability-adjusted life years (DALYs). ${ }^{[5]}$ In 2014, 28\% of DALYs and $12 \%$ of the overall burden of disease were predominantly due to four prevalent NCDs, including cardiovascular diseases (CVDs), cancer, chronic obstructive pulmonary diseases and diabetes. ${ }^{[6]}$ DALYs with regard to coronary heart diseases, stroke and diabetes resulted in a loss of USD1.88 billion between 2006 and 2015. ${ }^{\text {[7] }}$

While adults in their 70 s and older age groups are generally at greatest risk of dying from chronic diseases such as CVDs, death rates among this age group have reversed and continue to decline compared with the age groups 25 - 39 years, 40 - 54 years, and 55 - 69 years, showing less progressive patterns in the decline of the annual NCD-related death rate. ${ }^{[8]}$ It is presumed that high consumption of energy-dense foods, being overweight or obese, coupled with high rates of physical inactivity, have been accelerating this trend in the younger adult population. ${ }^{[8]}$ This could possibly be due to how the young adult population perceive the risks of NCDs compared with the older adult population.

The Health Belief Model (HBM) is one of the most effective health behaviour-change models that comprises six constructs (perceived susceptibility, severity, benefits, barriers, cues to action and selfefficacy), which explains why an individual may or may not adopt preventive measures against the disease of interest - NCDs in this case. ${ }^{[9]}$ Cross-sectional studies among Saudi female employees ${ }^{[10]}$ and rural Turkish women ${ }^{[1]}$ found that poor practice of monthly breast self-examination and mammography as preventive measures of breast cancer were not statistically significantly associated with age.

Furthermore, age did not predict women's attitudes towards this practice. Similar findings were reported in studies conducted in two villages near Kathmandu (Nepal $)^{[12]}$ and in Karachi (Pakistan) $)^{[13]}$ 
in relation to their attitude towards cardiovascular health ${ }^{[12]}$ and modifiable risk factors for heart diseases. ${ }^{[13]}$ In contrast, the level of knowledge and practice of cardiovascular health were statistically different according to age, ${ }^{[12]}$ where participants $<35$ years old were more likely to have a greater adequate knowledge and better practice than those who were $>45$ years of age. ${ }^{[12,13]}$ This was consistent with the results of other studies on knowledge of risk factors and prevention regarding diabetes in eastern Saudi Arabia, ${ }^{[14]}$ and of chronic diseases in Jinan (China). ${ }^{[15]}$ A cross-sectional study among black and Hispanic females in the USA found that younger-aged females ( $<55$ years) were less conscious of heart disease being the leading cause of mortality in women and were less likely to state that they were very well or knowledgeable concerning heart disease compared with older-aged women. ${ }^{[16]}$ Another study in the USA found that age was not a predictor of knowledge of perceived susceptibility and perceived self-efficacy to heart diseases among the African-American population. ${ }^{[17]}$

The role of age in the adoption of NCD preventive measures is contentious, as studies have disputed whether there is a positive or negative association between the two variables. ${ }^{[10,11,16,18,19]}$ However, findings of these studies cannot be generalised to Diepsloot's population owing to dissimilar sociodemographic characteristics. Studies in African settings on this topic are scarce, with none conducted in SA, especially among informal settlement dwellers, who are already at high risk of developing NCDs because of their unhealthy lifestyle. ${ }^{[20]}$ Health beliefs, attitudes and knowledge are key paradigms of health behaviour theories. In particular, perceptions of disease risk, control and severity are integrated into social cognitive models such as HBM, as they trigger health behaviours, mediate the impact of other risk factors, are flexible and responsive to change, and are targets for disease interventions. ${ }^{[21]}$ Consequently, the development of effective interventions for people at increased risk of NCDs is dependent upon understanding their beliefs concerning NCDs. NCD-related DALYs are expected to rise by $27 \%$ across regions of Africa compared with $17 \%$ globally by $2020,{ }^{[22,23]}$ with more than half occurring prematurely (in persons $<70$ years of age). ${ }^{[22,24]}$ In SA, adherence to the use of antiretroviral therapy (ART) has not only extended survival and ageing among HIVinfected individuals, but also supplemented the upsurge in NCD comorbidities among people living with HIV. ${ }^{[25,26]}$ The prevalence of dysglycaemia was 2 - 4-fold greater among HIV-infected groups compared with that in a community-based survey ${ }^{[25]}$ The prevalence of multimorbidities (hypertension and diabetes mellitus) was greater among people living with tuberculosis (TB) and younger HIVinfected individuals on ART compared with those without TB and HIV infection. ${ }^{[26]}$ A better understanding of the relationships between age groups and risk perceptions of NCDs is required. Our study is particularly important, as NCDs in SA occur simultaneously with an ageing HIV-positive population. ${ }^{[27]}$ This has important implications, as it will not only contribute towards the burden of premature deaths in Africa, but also worsen social inequities and poverty in informal settlements in SA because most expenses for healthcare are private and out-of-pocket; such expenses weigh more profoundly on individuals least capable of affording them. The results of this study will assist to inform, rationalise and substantiate the necessity for evidence-based policy, practice and behavioural change interventions aimed at improving adoption of NCD preventive measures in informal settlements as an approach to decrease the global burden of NCDs in SA. The aim of this study was to: (i) examine the relationships between age groups and risk perceptions of NCDs; and (ii) assess the distribution of risk perceptions of NCDs in relation to age groups.

\section{Methods}

\section{Study design}

This was a cross-sectional design using secondary data obtained from Community AIDS Response (CARe) in 2014, assessing risk perceptions of NCDs based on HBM in Extension 2 (Blocks I, J, K and L) of Diepsloot township, Johannesburg, SA.

\section{Study setting}

Diepsloot is a heavily crowded informal settlement in the extreme north of Johannesburg. ${ }^{[28,29]}$ It is situated in the recently formed Region A (formerly known as Region 1 and 2). ${ }^{[29]}$ It is currently residence to $\sim 360000$ individuals. ${ }^{[28]}$ The majority of the inhabitants are low socioeconomic class blacks. ${ }^{[29]}$ Nearly $73.7 \%$ of the 20 - 59-year age group are employable; ${ }^{[28,29]}$ nonetheless, unemployment rates remain high owing to low education levels. ${ }^{[28]}$ Consequently, many informal settlement dwellers are involved in criminal behaviour or run kiosks that sell alcohol, cigarettes or energy-dense foods at lower prices. This exposes other inhabitants to unhealthy lifestyles that increase their risk of becoming alcohol- and tobacco-dependent, and overweight/obese, which are well-known leading risk factors of NCDs. ${ }^{[26]}$

\section{Study population}

The study population comprised adults (females and males) living in Diepsloot in Blocks I, J, K and L of Extension 2, who were aged $\geq 20$ years.

\section{Inclusion criteria}

The following inclusion criteria were used in this study: $(i)$ informal residents living in Diepsloot; ( $i$ ) informal residents residing in either Block I, J, K, or L of Extension 2 in Diepsloot; and (iii) informal Diepsloot residents with a body mass index (BMI) $\geq 18.5 \mathrm{~kg} / \mathrm{m}^{2}$.

\section{Sampling and sample size}

The primary study utilised a systematic random sampling method. Every 7th informal settlement resident who underwent BMI assessment at the health campaign site was invited to participate in the survey. The selection procedure started from the 4th participant (starting point randomly chosen between numbers 1 and 7). A total of 2135 participants were surveyed by CARe.

As the dataset had many survey respondents (2 135), who also met the inclusion criteria of the study, and considering that the study did not require collecting primary data, all participants were included for analysis.

\section{Measurements}

The following variables were included in this study: gender, age, marital status, race, nationality, ethnicity, employment status, dwelling type, number of people in household, educational level, and BMI. Perceived susceptibility (perceptions about obesity, family medical history, smoking, unhealthy eating and physical inactivity as risk factors that could increase their risk for NCDs) was assessed by five items, measured on a 5-point Likert scale (strongly disagree, disagree, neutral, agree, and strongly agree). Perceived severity (perceptions about the seriousness of NCDs, and its consequences on the domains of life) was assessed by five items measured on a 5-point Likert scale (strongly disagree, disagree, neutral, agree, and strongly agree). Perceived benefits (perceptions about the effectiveness of taking health-promoting actions) were assessed by seven items measured on a 5-point Likert scale (strongly disagree, disagree, neutral, agree, and strongly agree). Perceived barriers (perceptions about changing one's behaviours to prevent NCD 
risk) were assessed by seven items measured on a 5-point Likert scale (strongly disagree, disagree, neutral, agree, and strongly agree). Perceived cues to action (participants' engagement in healthy behaviours to improve their health) were assessed by six items measured on a 5-point Likert scale (strongly disagree, disagree, neutral, agree, and strongly agree). Perceived self-efficacy (perceived ability to understand risks of NCDs and its prevention, as well as ability to change behaviour) was measured by five items on a 5-point Likert scale (strongly disagree, disagree, neutral, agree, and strongly agree).

The independent variable was age group. Participants were categorised in three mutually exclusive age groups (18 - 35 (young adults), 36 - 50 (middle-aged adults), and $>51$ (older adults) years) set a priori in accordance with the WHO age category guidelines for the sub-Saharan setting. ${ }^{[30]}$ The dependent variable comprised risk perceptions of NCDs based on HBM constructs (perceived susceptibility, severity, benefits, barriers, cues to action, and selfefficacy). We collapsed the 5-point Likert scale responses into binary measures. Strongly agree and agree responses were pooled together into agree, while strongly disagree, disagree and neutral responses were pooled together into disagree.

\section{Validity and reliability \\ Validity}

In the primary survey, two experienced reviewers evaluated the questionnaire for content and face validity. They assessed the grammar, syntax, appropriateness, relevance and flow of the questions. The reviewers confirmed that items within each HBM domain were suitable indicators of the constructs.

\section{Reliability}

For this study, Cronbach's alpha test was performed to: (i) assess internal consistency of items within each construct; (ii) assess if questions within each HBM domain in the primary survey questionnaire all reliably measured the same latent variable; and (iii) identify and consider whether any of the items (specific questions within each construct), which lower the internal consistency of the scale, were to be removed from the analysis. Cronbach's alpha coefficient for all constructs ranged between 0.78 and 0.89 for all constructs (Table 1). Cronbach's alpha coefficient for all the constructs met the standard of acceptable level of reliability (coefficient value of $\geq 0.70$ ) as recommended in the literature. ${ }^{[31,32]}$

\section{Data management}

The given dataset was in the format of an Excel spreadsheet, which we exported to STATA version 13 (Stata Corp., USA) to check for

\begin{tabular}{|c|c|c|}
\hline HBM constructs & $\begin{array}{l}\text { Items in the } \\
\text { scale, } n\end{array}$ & $\begin{array}{l}\text { Alpha- } \\
\text { coefficient }\end{array}$ \\
\hline Perceived susceptibility & 5 & 0.8133 \\
\hline Perceived severity & 5 & 0.8357 \\
\hline Perceived benefits & 7 & 0.7791 \\
\hline Perceived barriers & 7 & 0.8655 \\
\hline Perceived cues to action & 5 & 0.7832 \\
\hline Perceived self-efficacy & 6 & 0.8414 \\
\hline
\end{tabular}

data completeness, outliers' missing data, grouping and coding variables and performing statistical analysis accordingly. All data were stratified by age groups. The data were found to be complete, with no missing variables. We collapsed variables with 5-point Likert scale responses into binary measures. Strongly agree and agree responses were grouped into agree, while strongly disagree, disagree and neutral responses were grouped into disagree. These were coded as follows: $0=$ agree and $1=$ disagree.

\section{Data analysis}

Descriptive statistics were used to summarise and describe the data. Numerical data were summarised as means and standard deviations (SDs). Categorical data were summarised as frequencies and percentages. Pearson's $\chi^{2}$ test was used to examine whether differences in baseline characteristics between young adults, middle-aged adults and older-aged adults were statistically significant. Pearson's $\chi^{2}$ test of independence was used to examine the association between dependent and independent variables. A $p$-value $<0.05$ was considered statistically significant.

\section{Ethical considerations}

Ethical clearance for this study was sought from Monash University Human Research Ethics Committee (ref. no. CF14/2803-2014001558) as part of a larger study. Authorisation to use the dataset for this study was given by CARe. The data were used anonymously.

\section{Results}

\section{Baseline characteristics of study participants}

Table 2 shows the baseline characteristics of survey participants stratified by age groups. A total of 2135 participants were included in the analysis, of whom 1154 (54.05\%) were females. Most of the survey participants were 18 - 35 years old ( $n=1526$, $71.48 \%$ ) and the mean age was 31.2 (SD 9.87) years. The majority of the participants were from black communities $(n=2111$, $98.88 \%$ ) with poor socioeconomic status, living in informal houses (shacks) ( $n=1740,81.50 \%)$. Gender $(p<0.001)$, employment status ( $p=0.025)$, nationality $(p=0.001)$, marital status $(p<0.001)$, type of dwelling ( $p=0.001)$, highest education qualification $(p<0.001)$ and monthly income $(p=0.001)$ had a statistically significant variation between young, middle-aged and older-aged adult participants (Table 2).

\section{Association between age group and HBM constructs}

This section reports analysis of the $\chi^{2}$ test of independence comparing association between risk perceptions of NCDs and age group as a factor.

\section{Perceived susceptibility}

In the perceived susceptibility construct, variables were independently associated with age group as a factor. These variables include family medical history $\left(\chi^{2}(2)=6.2020, p=0.045\right)$ and smoking $\left(\chi^{2}(2)=11.0176, p=0.004\right)$. These factors were significantly associated with age groups, with more middle-aged adults perceiving these as risk factors that would increase their risk of NCDs than young and older-aged adults.

\section{Perceived severity}

In the perceived severity construct, variables were independently associated with age group as a factor. These variables impact on life and family $\left(\chi^{2}(2)=10.9161, p=0.004\right)$ and adverse thoughts $\left(\chi^{2}(2)=7.5548, p=0.023\right)$. They were significantly associated with age group, with more middle-aged adults perceiving these factors as risks of NCD morbidities than young and older-aged adults. 
Table 2. Baseline demographic characteristic of study participants stratified by age groups

\begin{tabular}{|c|c|c|c|c|c|}
\hline Variables & $\begin{array}{l}\text { Total } \\
(N=2 \text { 135) }\end{array}$ & $\begin{array}{l}\text { Young adults } \\
(18-35 \text { years, } \\
n=1526)(71.48 \%)\end{array}$ & $\begin{array}{l}\text { Middle-aged adults } \\
(36-50 \text { years, } \\
n=500)(23.42 \%)\end{array}$ & $\begin{array}{l}\text { Older-aged adults } \\
\text { ( } \geq 51 \text { years, } \\
n=109)(5.11 \%)\end{array}$ & $p$-value \\
\hline Mean age (SD) & $32.1(9.87)$ & & & & \\
\hline \multicolumn{6}{|l|}{ Gender, $n(\%)$} \\
\hline Female & $1154(54.05)$ & $867(56.82)$ & $243(48.60)$ & $44(40.37)$ & $0.000^{*}$ \\
\hline Male & $981(45.95)$ & $659(43.18)$ & $257(51.40)$ & $65(59.63)$ & \\
\hline \multicolumn{6}{|l|}{ Ethnicity, $n(\%)$} \\
\hline Black & $2111(98.88)$ & $1505(98.62)$ & $497(99.40)$ & $109(100.00)$ & 0.188 \\
\hline Coloured & $24(1.12)$ & $21(1.38)$ & $3(0.60)$ & $0(0.00)$ & \\
\hline \multicolumn{6}{|c|}{ Employment status, $n(\%)$} \\
\hline Employed & $273(12.79)$ & $184(12.06)$ & $80(16.00)$ & $9(8.26)$ & $0.025^{*}$ \\
\hline Unemployed & $1862(87.21)$ & $1342(87.94)$ & $420(84.00)$ & $100(91.74)$ & \\
\hline \multicolumn{6}{|l|}{ Nationality, $n(\%)$} \\
\hline South African & $1860(87.12)$ & $1304(85.45)$ & $455(91.00)$ & $101(92.66)$ & $0.001^{*}$ \\
\hline Non-South African & $275(12.88)$ & $222(14.55)$ & $45(9.00)$ & $8(7.34)$ & \\
\hline \multicolumn{6}{|l|}{ Marital status, $n(\%)$} \\
\hline Cohabitating & $6(0.28)$ & $0(0.00)$ & $6(1.20)$ & $0(0.00)$ & $0.000^{*}$ \\
\hline Divorced & $25(1.17)$ & $8(0.52)$ & $8(1.60)$ & $9(8.26)$ & \\
\hline Married & $510(23.89)$ & $268(17.56)$ & $200(40.00)$ & $42(38.53)$ & \\
\hline Single & $1586(74.29)$ & $1250(81.91)$ & $281(56.20)$ & $55(50.46)$ & \\
\hline Widow & $8(0.37)$ & $0(0.00)$ & $5(1.00)$ & $3(2.75)$ & \\
\hline \multicolumn{6}{|l|}{ Type of dwelling, $n(\%)$} \\
\hline House & $395(18.50)$ & $253(16.58)$ & $121(24.20)$ & $21(19.27)$ & $0.001^{*}$ \\
\hline Shack & $1740(81.50)$ & $1273(83.42)$ & $379(75.80)$ & $88(80.73)$ & \\
\hline \multicolumn{6}{|c|}{ People in household, $n(\%)$} \\
\hline Alone & $79(3.70)$ & $56(3.67)$ & $23(4.60)$ & $0(0.00)$ & 0.043 \\
\hline $2-5$ & $1128(52.83)$ & $794(52.03)$ & $280(56.00)$ & $54(49.54)$ & \\
\hline $6-10$ & $928(43.47)$ & $676(44.30)$ & $197(39.40)$ & $55(50.46)$ & \\
\hline \multicolumn{6}{|c|}{ Highest education qualification, $n(\%)$} \\
\hline Certificate & $75(3.51)$ & $56(3.67)$ & $19(3.80)$ & $0(0.00)$ & $0.000^{*}$ \\
\hline Degree & $37(1.73)$ & $31(2.03)$ & $6(1.20)$ & $0(0.00)$ & \\
\hline Diploma & $77(3.61)$ & $54(3.54)$ & $23(4.60)$ & $0(0.00)$ & \\
\hline Matric & $744(34.85)$ & $518(33.94)$ & $212(42.40)$ & $14(12.84)$ & \\
\hline No matric & $1202(56.30)$ & $867(56.82)$ & $240(48.00)$ & $95(87.16)$ & \\
\hline \multicolumn{6}{|l|}{ Monthly income, $n(\%)$} \\
\hline$<$ ZAR1 000 & $1862(87.21)$ & $1342(87.94)$ & $420(84.00)$ & $100(91.74)$ & $0.001^{*}$ \\
\hline ZAR1 $000-4999$ & $225(10.54)$ & $161(10.55)$ & $58(11.60)$ & $6(5.50)$ & \\
\hline > ZAR4 999 & $48(2.25)$ & $23(1.51)$ & $22(4.40)$ & $3(2.75)$ & \\
\hline \multicolumn{6}{|l|}{ BMI (\%) } \\
\hline Overweight/obese & $1285(61.37)$ & $923(61.70)$ & $302(61.13)$ & $60(57.69)$ & 0.714 \\
\hline Normal weight & $809(38.63)$ & $573(38.30)$ & $192(38.87)$ & $44(42.31)$ & \\
\hline
\end{tabular}

\section{Perceived benefits}

In the perceived benefits construct, six variables were independently associated with age group as a factor. These variables include physical activity $\left(\chi^{2}(2)=11.6180, p=0.003\right)$, healthy lifestyle $\left(\chi^{2}(2)=20.0129\right.$, $p<0.001)$, weight management $\left(\chi^{2}(2)=28.4892, p<0.001\right)$, not smoking $\left(\chi^{2}(2)=7.1273, p=0.028\right)$, and regular health check-ups $\left(\chi^{2}(2)=24.0826\right.$, $p<0.001)$. These factors were significantly associated with age group, with more older-aged adults perceiving the usefulness of these factors as NCD preventive measures compared with young and middle-aged adults. 


\section{Perceived barriers}

The perception of health check-ups as a time-consuming process was significantly associated with age group $\left(\chi^{2}(2)=13.5714, p=0.001\right)$. This association was greater among young adults compared with middle-aged and older-aged adults.

\section{Perceived cues to action}

The perception of eating small portions to improve health was significantly associated with age group $\left(\chi^{2}(2)=13.7513, p=0.001\right)$. This association was greater among middle-aged adults compared with young and older-aged adults.

\section{Perceived self-efficacy}

The perception of having confidence to understand NCD risks and prevention was significantly associated with age group $\left(\chi^{2}(2)=17.3554\right.$, $p<0.001)$. This association was higher among middle-aged adults compared with young and older-aged adults. There was a statistically significant association between age group and the perception of having health information to understand risks of NCDs and its prevention $\left(\chi^{2}(2)=6.3745, p=0.041\right)$. The association was greater among middle-aged adults than young and older-aged adults. The perception of having the ability to actively work on health to prevent risk of NCDs was significantly associated with age group $\left(\chi^{2}(2)=17.3554\right.$, $p<0.001)$. This association was higher among middle-aged adults than young and older-aged adults.

\section{Distribution of risk perceptions of NCDs stratified by age groups}

Table 3 compares the distribution of risk perceptions of NCDs by age groups.

\section{Perceived susceptibility}

Significant variations between young adults, middle-aged adults and older-aged adults were found in the perceived susceptibility construct. The proportion of perceived susceptibility to risks of NCDs among middle-aged adults was greater than for young and older-aged adults, and the difference was statistically significant. A greater proportion of middle-aged adults compared with young and older-aged adults perceived family history $(74.00 \%$ v. $72.74 \%$ v. $62.39 \%, p=0.045)$ and smoking $(83.80 \%$ v. $77.20 \%$ v. $74.31 \%, p=0.004)$ as risk factors that would increase their risk of NCDs. The differences were statistically significant.

\section{Perceived severity}

A higher proportion of older-aged adults than young and middleaged adults perceived effects on life and family $(89.91 \%$ v. $77.39 \%$ v. $75.40 \%, p=0.004)$ and adverse thoughts $(89.91 \%$ v. $82.50 \%$ v. $79.20 \%, p=0.023)$ as risks of NCD morbidities. The differences were statistically significant. Significantly more middle-aged adults compared with young and older-aged adults perceived change in outlook as a risk of NCD morbidities $(82.40 \%$ v. $74.71 \%$ v. $70.64 \%$, $p=0.001$ ). The differences were statistically significant (Table 3 ).

\section{Perceived benefits}

The perceived benefits of adopting health-promoting behaviours with regard to the risk of NCDs were greater in middle-aged adults than young and older-aged adults. The differences were statistically significant. More middle-aged adults than young and older-aged adults perceived the usefulness of physical activities $(84.40 \%$ v. $82.31 \%$ v. $70.64 \%, p=0.003)$, healthy lifestyle $(87.20 \%$ v. $82.90 \%$ v. $69.72 \%$, $p<0.001$ ), weight management ( $89.00 \%$ v. $83.09 \%$ v. $68.81 \%, p<0.001)$, not smoking $(84.60 \%$ v. $81.06 \%$ v. $74.31 \%, p=0.028)$, and regular health check-ups $(87.20 \%$ v. $80.01 \%$ v. $68.81 \%, p<0.001)$ as effective NCD preventive measures. The differences between age groups in each of these variables were statistically significant (Table 3 ).

\section{Perceived barriers}

Among the potential barriers, more young adults compared with middle-aged and older-aged adults perceived health check-ups as a time-consuming process to prevent risks of NCDs $(59.31 \%$ v. $58.00 \%$ v. $41.28 \%, p=0.001)$. The difference was statistically significant. This barrier prevents them from adopting NCD preventive measures and understanding that health check-ups have an influence on NCDs (Table 3).

\section{Perceived cues to action}

The perception of eating small portions to improve health was greater among middle-aged adults than young and older-aged adults $(40.00 \% \mathrm{v}$. $74.97 \%$ v. $61.47 \%, p=0.001)$. The difference was statistically significant.

\section{Perceived self-efficacy}

The proportion of perceived self-efficacy to the risks of NCDs among middle-aged adults was higher than in young and older-aged adults. The differences were statistically significant. There were more middleaged adults than young and older-aged adults who perceived to have the confidence $(78.40 \%$ v. $74.97 \%$ v. $61.47 \%, p<0.001)$ and health information $(84.00 \%$ v. $79.10 \%$ v. $77.06 \%, p=0.041)$ to understand the risks of NCDs and its prevention, as well as the ability to actively work on a healthy lifestyle $(80.40 \%$ v. $77.85 \%$ v. $55.96 \%, p<0.001)$. The differences were statistically significant (Table 3 ).

\section{Discussion}

The purpose of this study was to examine age-group differences in risk perceptions of NCDs among adults in Diepsloot township. Studies assessing this topic in African settings are scarce, with none in SA. Therefore, studies conducted in other countries were used to support the results of this study. Although several studies across developed and developing countries have examined knowledge, attitude and practice of preventive measures among individuals at increased risk of different NCDs, particularly breast cancer in females, ${ }^{[10,11,18,32]}$ diabetes, ${ }^{[1,21]}$ and CVDs, ${ }^{[12,13,16,33-38]}$ this is the first identifiable study that explored the relationship between age groups and risk perceptions of NCDs, based on all the constructs of the HBM.

Knowledge is factual, objective and justified truth. Beliefs, however, are mental representations of one's thoughts from a cognitive point of view towards the likelihood of something being true. ${ }^{[39]}$ Considering that: (i) biochemistry of knowledge and beliefs are different; and (ii) to our knowledge no literature has focused on individuals of specific age groups and their health beliefs of risk perceptions of NCDs, studies exploring similar concepts but in relation to NCD knowledge and attitude in particular cannot be used to support the results of this study. Instead, the results are explained by the HBM and other related theoretical frameworks. The results are unique findings that in many ways may influence existing and new NCD policies and programmes in SA.

Our study found that more young adults perceived the risks of NCDs to be lower than middle-aged and older-aged adults - predominantly family history and smoking as risk factors of NCDs, negative impact on life and family, outlook, and adverse thoughts as effects of NCDs morbidities. This could be because they lacked more confidence with regard to health information to understand the risks of NCDs and their prevention than middleaged and older-aged adult participants. Furthermore, more young 
Table 3. Distribution of risk perceptions of NCDs stratified by age groups

\begin{tabular}{|c|c|c|c|c|}
\hline Variables & $\begin{array}{l}\text { Young adults } \\
(18-35 \text { years, } \\
n=1526)(72.48 \%), \\
\text { agree }\end{array}$ & $\begin{array}{l}\text { Middle-aged adults } \\
(36-50 \text { years, } \\
n=500)(23.42 \%), \\
\text { agree }\end{array}$ & $\begin{array}{l}\text { Older-aged adults } \\
(\geq 51 \text { years, } n=109) \\
(5.11 \%), \text { agree }\end{array}$ & $p$-value \\
\hline \multicolumn{5}{|l|}{ Perceived susceptibility, $n$ (\%) } \\
\hline Being obese/overweight will lead me to getting NCDs & $1169(76.61)$ & $377(75.40)$ & $79(72.48)$ & 0.567 \\
\hline My family medical history makes it likely to get NCDs & $1110(72.74)$ & $370(74.00)$ & $68(62.39)$ & $0.045^{*}$ \\
\hline Smoking makes it likely to get NCDs & $1178(77.20)$ & $419(83.80)$ & $81(74.31)$ & $0.004^{*}$ \\
\hline Unhealthy eating habits can make me get NCDs & $1149(75.29)$ & $389(77.80)$ & $81(74.31)$ & 0.488 \\
\hline Physical inactivity can make me get NCDs & $1203(78.83)$ & $391(78.20)$ & $81(74.31)$ & 0.534 \\
\hline \multicolumn{5}{|l|}{ Perceived severity, $n(\%)$} \\
\hline $\begin{array}{l}\text { Having an NCD will have major effects on my life and } \\
\text { family }\end{array}$ & $1181(77.39)$ & $377(75.40)$ & $98(89.91)$ & $0.004^{*}$ \\
\hline $\begin{array}{l}\text { Having an NCD will have major effects on my work and } \\
\text { income }\end{array}$ & $1184(77.59)$ & $372(74.40)$ & $87(79.82)$ & 0.261 \\
\hline Having an NCD will cripple me & $1183(77.52)$ & $385(77.00)$ & $83(76.15)$ & 0.928 \\
\hline Having an NCD will change my outlook & $1140(74.71)$ & $412(82.40)$ & $77(70.64)$ & $0.001^{*}$ \\
\hline Thought of having NCDs scares me & $1259(82.50)$ & $396(79.20)$ & $98(89.91)$ & $0.023^{*}$ \\
\hline \multicolumn{5}{|l|}{ Perceived benefits, $n$ (\%) } \\
\hline Not having an NCD is beneficial & $1198(78.51)$ & $381(76.20)$ & $83(76.15)$ & 0.508 \\
\hline Physical activities prevent NCDs & $1256(82.31)$ & $422(84.40)$ & $77(70.64)$ & $0.003^{*}$ \\
\hline Healthy lifestyle prevents NCDs & $1265(82.90)$ & $436(87.20)$ & $76(69.72)$ & $<0.001^{\star}$ \\
\hline Managing weight prevents NCDs & $1268(83.09)$ & $445(89.00)$ & $75(68.81)$ & $<0.001^{\star}$ \\
\hline Not smoking prevents NCDs & $1237(81.06)$ & $423(84.60)$ & $81(74.31)$ & $0.028^{*}$ \\
\hline Regular health check-ups will detect NCDs early & $1221(80.01)$ & $436(87.20)$ & $75(68.81)$ & $<0.001^{*}$ \\
\hline Regular health check-ups are beneficial & $1207(79.10)$ & $363(72.60)$ & $81(74.31)$ & $0.008^{*}$ \\
\hline \multicolumn{5}{|l|}{ Perceived barriers, $n(\%)$} \\
\hline Very little can be done to prevent NCDs & $912(59.76)$ & $311(62.20)$ & $79(72.48)$ & $0.026^{*}$ \\
\hline No treatment will be effective in curing NCDs & $800(52.42)$ & $292(58.40)$ & $74(67.89)$ & $0.001^{\star}$ \\
\hline Healthy foods are expensive & $971(63.63)$ & $316(63.20)$ & $65(59.63)$ & 0.703 \\
\hline Health check-ups are expensive & $869(56.95)$ & $277(55.40)$ & $59(54.13)$ & 0.735 \\
\hline Preparing healthy foods is time-consuming & $901(59.04)$ & $271(54.20)$ & $56(51.38)$ & 0.068 \\
\hline Health check-ups are time-consuming & $905(59.31)$ & $290(58.00)$ & 45 (41.28) & $0.001^{*}$ \\
\hline It is embarrassing to go for health check-ups & $838(54.91)$ & $262(52.40)$ & $48(44.04)$ & 0.069 \\
\hline \multicolumn{5}{|l|}{ Perceived cues to action, $n(\%)$} \\
\hline I eat a well-balanced diet & $1097(71.89)$ & $304(60.80)$ & $78(71.56)$ & $<0.001^{*}$ \\
\hline I always follow medical orders to benefit my health & $1134(74.31)$ & $359(71.80)$ & $81(74.31)$ & 0.536 \\
\hline I frequently make efforts to improve my health & $1112(72.87)$ & $370(74.00)$ & $81(74.31)$ & 0.854 \\
\hline I exercise regularly, at least 3 times per week & $1137(74.51)$ & $385(77.00)$ & $84(77.06)$ & 0.481 \\
\hline I avoid fatty foods & $1135(74.38)$ & $372(74.40)$ & $75(68.81)$ & 0.433 \\
\hline I eat small-portion meals & $1144(74.97)$ & $392(78.40)$ & $67(61.47)$ & $0.001^{*}$ \\
\hline \multicolumn{5}{|l|}{ Perceived self-efficacy, $n$ (\%) } \\
\hline I am confident about how to prevent chronic diseases & $1183(77.52)$ & $399(79.80)$ & $67(61.47)$ & $<0.001^{*}$ \\
\hline $\begin{array}{l}\text { I am able to actively work on a healthy lifestyle to prevent } \\
\text { NCDs }\end{array}$ & $1188(77.85)$ & $402(80.40)$ & $61(55.96)$ & $<0.001^{*}$ \\
\hline I attend health assessments to prevent NCDs & $1179(77.26)$ & $380(76.00)$ & $75(68.81)$ & 0.125 \\
\hline I have information on how to prevent NCDs & $1207(79.10)$ & $420(84.00)$ & $84(77.06)$ & $0.041^{*}$ \\
\hline $\begin{array}{l}\text { There is a lot I can do to reduce my chances of getting an } \\
\text { NCD-related illness }\end{array}$ & $1097(71.89)$ & $304(60.80)$ & $78(71.56)$ & $<0.001^{*}$ \\
\hline
\end{tabular}


adults did not have a matriculation qualification than middleaged and older-aged adults. This is concerning, as a low level of literacy is one of the leading factors influencing unhealthy and risky behaviours. ${ }^{[40]}$ As unemployment and alcohol and drug abuse are some of the most pressing social problems among youths in Diepsloot, ${ }^{[28]}$ it is possible that young adults are least exposed to NCD information as they go out to look for money to be able to purchase alcohol and drugs. Hence, they are less likely to access services such as HIV testing and counselling, which also provide NCD-related knowledge.

Poor perception of smoking as a risk factor of NCDs and the usefulness of not smoking as an effective NCD preventive measure among young adults is of concern. In accordance with the theory of invincibility, young adults often believe themselves to be invincible, which leads to the perception that somehow the consequences of their engagement in a particular behaviour will not happen, as they are invulnerable. ${ }^{[41]}$ Therefore, they often underestimate the risks associated with their behaviour (i.e. smoking). There is therefore a need to consider revising SA's existing tobacco policy by integrating outreach and public health education programmes involving community leaders to reach out to more young adults in informal settlements. These are cost-effective and successful methods of escalating knowledge and awareness, ${ }^{[42,43]}$ chronic obstructive pulmonary disease and lung cancer. It is noteworthy that the likelihood of perceiving oneself at greater risk escalates when the presence of a risk factor is known. ${ }^{[12]}$ Risk indicators, for instance the number of cigarettes smoked, account for $24.0 \%$ variation in perceived risk. ${ }^{[4]}$ However, the primary survey questionnaire did not capture the participants' smoking behaviours. Therefore, there is a possibility that many young adults may not have been smokers and did not perceive smoking as a risk of NCDs.

Regular health check-ups are known to be effective in detecting and treating chronic diseases at an early stage. We found that young adults were less likely to perceive the usefulness of regular health assessments as an effective NCD preventive measure than middleaged and older-aged adults. This could be because young adults were more likely to perceive health assessments as a time-consuming process compared with middle-aged and older-aged adults, which indicates a need to increase efforts to reach out to more young adults and educate them about the benefits associated with routine health check-ups.

Young adults were less likely to eat small-portion meals to improve their health compared with middle-aged and older-aged adults. This could be because they were less likely to perceive the usefulness of weight management in preventing NCDs, which indicates that poor risk perceptions of NCDs have a negative impact on adoption of NCD preventive measures. There is a possibility that this observed difference could have been confounded by gender, as perceptions of weight management varies by gender in African culture, where being overweight/obese has positive connotations. ${ }^{[55,46]}$ According to an African-based study in Khayelitsha township in Cape Town, SA, Puoane et al. ${ }^{[46]}$ revealed that being overweight was more ideal and preferred among black women because it signified that one is being taken good care of by one's spouse. Alternatively, from a male's point of view, it inferred that such women are healthier, capable to stir large pots, and would not be blown away by the strong Cape winds; desirability by males escalates as females become obese. ${ }^{[45]}$ In light of this, our study did not account for gender.

\section{Study strengths and limitations}

This was the first study describing specific age-group differences in risk perceptions of NCDs in an informal settlement in SA. There had been a case study in Diepsloot describing the risk perceptions of NCDs using the HBM, but age-group differences were not reported. ${ }^{[20]}$ However, our study has several limitations. It had a cross-sectional design, which did not allow making any causal inferences on the established associations found. The $p$-values only indicate existence of a relationship between two variables - not the strength of the relationship or which relationship is the most significant in each HBM construct. ${ }^{[47]}$ The method of selecting the study participants in the primary survey might have introduced selection bias, assuming that those not selected because they did not undergo BMI assessment might have reported risk perceptions of NCDs differently. Moreover, data were self-reported; therefore, some survey participants might have over-reported socially desirable perceptions and behaviours.

\section{Conclusion}

More young adults had poor risk perceptions of NCDs than middleaged and older-aged adults in Diepsloot township. They were less likely to adopt healthy behaviours compared with middle-aged and older-aged adults, which indicates that poor risk perceptions can negatively impact the uptake of prevention measures. This could be due to the misconception of the concept of invulnerability, possibly resulting from limited exposure to NCD-related information among young adults to understand NCD-related risks and prevention. This highlights the need to increase public health education programmes to increase outreach, NCDs knowledge and uptake of prevention measures, particularly among young adults. Further research could investigate gender differences in risk perceptions of NCDs among this population, which could provide a better understanding or possible explanation of the less positive trends in decrease of NCDrelated mortalities among the younger population.

Acknowledgements. We would like to thank the CARe organisation, Johannesburg, SA, for providing the dataset used in this study.

Author contributions. ZK: conceptualised the study, performed the statistical analysis of the secondary data, interpreted the data and results, alongside writing and revising the manuscript and scientific content. NK: supervised the study, provided essential constructs for the writing of the manuscript and interpretation of the results, and supervised the revision of important scientific content. NT: gave advice on the presentation of the results and editing of the manuscript text. All authors read and approved the final version of the manuscript.

Funding. None.

Conflicts of interest. None.

1. Richards NC, Gouda HN, Durham J, Rampatige R, Rodney A, Whittaker M. Disability, noncommunicable disease and health information. Bull World Health Organ 2016;94(3):230-232. https://doi.org/10.2471/BLT.15.156869

2. World Health Organization. Global Status Report on Noncommunicable Diseases 2014. Geneva: WHO, 2014:1-176.

3. World Health Organization. Global Status Report on Noncommunicable Diseases 2010. Italy: WHO, 2011:1-176.

4. Hunter D, Reddy SK. Noncommunicable diseases. N Engl J Med 2013;369(14):1336-1343. https://doi. org/10.1056/NEJMra1109345

Beaglehole R, Bonita R, Horton R, et al. Priority actions for the non-communicable disease crisis. Lancet 2011;377(9775):1438-1447. https://doi.org/10.1016/S0140-6736(11)60393-0

6. World Health Organization. NCD Profile South Africa. Geneva: WHO, 2014:1-210

6. World Health Organization. NCD Profile South Africa. Geneva: WHO, 2014:1-210.
7. Hofman K. Non-communicable diseases in South Africa: A challenge to economic development. Hofman K. Non-communicable diseases in South Africa: A chall

8. Australian Institute of Health and Welfare. Trends in Coronary Heart Disesase Mortality: Age Groups Australian Institute of Health and Welfare. Trends in Coronary Heart Disesase
and Populations: Cardiovascular Disease Series. Canberra: AIHW, 2014:1-38.

9. Onoruoiza SI, Musa A, Umar BD, Kunle YS. Using health belief model as an intervention to noncompliance with hypertension information among hypertensive patient. Int Organ Sci Res J Human Soc Sci 2015;20(9):11-16. https://doi.org/10.9790/0837-20951116

10. Abolfotouh MA, BaniMustafa AA, Mahfouz AA, Al-Assiri MH, Al-Juhani AF, Alaskar AS. Using the health belief model to predict breast self examination among Saudi women. BioMed Central Public Health 2015;15(1):1-12. https://doi.org/10.1186/s12889-015-2510-y

11. Dündar PE, Ozmen D, Oztürk B, et al. The knowledge and attitudes of breast self-examination and mammography in a group of women in a rural area in western Turkey. BioMed Central Cancer 2006;6(43):1-9. https://doi.org/10.1186/1471-2407-6-43 
12. Vaidya A, Aryal UR, Krettek A. Cardiovascular health knowledge, attitude and practice/behaviour in an urbanising community of Nepal: A population-based cross-sectional study from JhaukhelDuwakot Health Demographic Surveillance Site. BioMed Central J Open 2013;3(10):e002976. https:// doi.org/10.1136/bmjopen-2013-002976

13. Khan MS, Jafary FH, Jafar TH, et al. Knowledge of modifiable risk factors of heart disease among patients with acute myocardial infarction in Karachi, Pakistan: A cross sectional study. BioMed Central Cardiovasc Dis 2006;6(18):1-9. https://doi.org/10.1186/1471-2261-6-18

14. Aljoudi AS, Taha AZ. Knowledge of diabetes risk factors and preventive measures among attendees of a primary care center in eastern Saudi Arabia. Ann Saudi Med 2011;1(29):15-19. https://doi. org/10.4103/0256-4947.51813

15. Song Y, Ma W, Yi X, et al. Chronic diseases knowledge and related factors among the elderly in Jinan, China. PLoS ONE 2013;8(6):e68599. https://doi.org/10.1371/journal.pone.0068599

16. Mochari-Greenberger H, Miller KL, Mosca L. Racial/ethnic and age differences in women's awarenes of heart disease. J Women's Health 2012;21(5):476-480. https://doi.org/10.1089/jwh.2011.3428

17. Winham DM, Jones KM. Knowledge of young African American adults about heart disease: A crosssectional survey. BioMed Central Public Health 2011;11(248):1-11. https://doi.org/10.1186/1471-245811-248

18. Agboola AOJ, Deji-Agboola AM, Oritogun KS, Musa AA, Oyebadejo TY, Ayoade BA. Knowledge, attitude and practice of breast self examination in female health workers in Olabisi Onabanjo University Teaching Hospital, Sagamu, Nigeria. Int Med J Malaysia 2009;8(1):5-10.

19. Mosca L, Benjamin EJ, Berra K, et al. Effectiveness-based guidelines for the prevention of cardiovascular disease in women - 2011 update. J Am Coll Cardiol 2011;57(12):1404-1423. https://doi.org/10.1016/. jacc.2011.02.005

20. Tshuma N. Perceptions of risk of non-communicable diseases associated with overweight and obesity among individuals living in Diepsloot informal settlements, Johannesburg, South Africa. S Am J Public Health 2014;2(4):629-665

21. Dorman JS, Valdez R, Liu T, et al. Health beliefs among individuals at increased familial risk for type 2 diabetes: Implications for prevention. Diabet Res Clin Pract 2012;96(2):156-162. https://do. org/10.1016/.diabres.2011.12.017

22. World Health Organization. Global Action Plan for the Prevention and Control of Noncommunicable Diseases 2013 - 2020. Geneva: WHO, 2013:1-102.

23. Islam SMS, Purnat TD, Phuong NTA, Mwingira U, Schacht K, Fröschl G. Non-communicable disease (NCDs) in developing countries: A symposium report. Global Health 2014;10(81):1-7. https://doi. org/10.1186/s12992-014-0081-9

24. Abegunde DO, Mathers CD, Adam T, Ortegon M, Strong K. The burden and costs of chronic diseases in low-income and middle-income countries. Lancet 2007;370(9603):1929-1938. https://doi diseases in low-income and middle-

25. Levitt NS, Peer N, Steyn K, et al. Increased risk of dysglycaemia in South Africans with HIV especially those on protease inhibitors. Diabet Res Clin Prac 2016;119:41-47. https://doi.org/10.1016/. diabres.2016.03.012

26. Oni T, Youngblood E, Boulle A, McGrath N, Wilkinson R, Levitt NS. Patterns of HIV, TB, and noncommunicable disease multi-morbidity in peri urban South Africa - a cross sectional study. BioMed Central Infect Dis 2015;15(20):1-8. https://doi.org/10.1186/s12879-015-0750-1

27. Collins DL, Leibbrandt M. The financial impact of HIV/AIDS on poor households in South Africa. AIDS 2007;21(suppl 7):S75-S81. https://doi.org/10.1097/01.aids.0000300538.28096.1c

28. Johannesburg Development Agency. Diepsloot Ready for Development. Johannesburg: JDA, 2013:1-8.

29. Statistics South Africa. Census 2011 Fact sheet. Pretoria: Statistics South Africa, 2011:1-2.

30. World Health Organization. Health Statistics and Health Information Systems: Definition of an Older or Elderly Person. Proposed Working Definition of an Older Person in Africa for the MDS Project. Geneva: WHO, 2001.
31. DeVon HA, Block ME, Moyle-Wright P, et al. A psychometric toolbox for testing validity and reliability. J Nursing Scholar 2007:39(2):155-164. https://doi.org/10.1111/ji.1547-5069.2007.00161 x

32. Wong RK, Wong ML, Chan YH, Feng Z, Wai CT, Yeoh KG. Gender differences in predictors of colorectal cancer screening uptake: A national cross sectional study based on the health belief model. colorectal cancer screening uptake: A national cross sectional study based on the health belief model.
BioMed Central Public Health 2013;13(677):1-12. https://doi.org/10.1111/j.1547-5069.2007.00161.x

33. Abbaszadeh A, Borhani F, Asadi N. Effects of health belief model-based video training about risk factors on knowledge and attitude of myocardial infarction patients after discharge. J Res Med Sci 2011;16(2):195-200.

34. Ali NS. Prediction of coronary heart disease preventive behaviors in women: A test of the Health Belief Model. Women Health 2002;242(2002):83-96. https://doi.org/10.1300/J013v35n01_06

35. Oli N, Vaidya A, Subedi M, Krettek A. Experiences and perceptions about cause and prevention of cardiovascular disease among people with cardiometabolic conditions: Findings of in-depth interviews from a peri-urban Nepalese community. Global Health Action 2014;7(1):1-11. https://doi.org/10.3402/ gha.v7.24023

36. Katz DA, Graber M, Birrer E, et al. Health beliefs toward cardiovascular risk reduction in patients admitted to chest pain observation units. Acad Emerg Med 2009;16(5):379-387. https://doi.org/10.1111/ $1553-2712.2009 .00383 . x$

37. Tovar E, Clark MC. Knowledge and health beliefs related to heart disease risk among adults with type 2 diabetes. J Am Assoc Nurse Pract 2014;27(6):1-7. https://doi.org/10.1002/2327-6924.12172

38. Choi S, Rankin S, Stewart A, Oka R. Perceptions of coronary heart disease risk in Korean immigrants with type 2 diabetes. Diabet Educ 2013;34(3):484-492. https://doi.org/10.1177/0145721708316949

39. Rao TSS, Asha MR, Rao KSJ, Vasudevaraju P. The biochemistry of belief. Ind J Psychiat 2009;51(4):239-241. https://doi.org/10.4103/0019-5545.58285

40. Hosseinpoor AR, Bergen N, Kunst A, et al. Socioeconomic inequalities in risk factors for non communicable diseases in low-income and middle-income countries: Results from the World Health Survey. BioMed Central Public Health 2012;12(1):912. https://doi.org/10.1186/1471-2458-12-912

41. Killgore WDS, Kelley A, Balkin TJ. So you think yoưre bulletproof: Development and validation of the Invincibility Belief Index (IBI). Mil Med 2010;175(7):499-508. https://doi.org/10.7205/MILMED-D-09-00240

42. Schroetter SA, Peck SD. Women's risk of heart disease: Promoting awareness and prevention - a primary care approach. Medsurg Nursing (Lond) 2008;17(2):107-114

43. Tavassoli E, Reisi M, Javadzad SH, et al. The effect of education on the improvement of fruits and vegetables consumption aiming to preventing colorectal cancer. Med J Islam Rep Iran 2015;29(183):1-7.

44. Chen W, Yu Y, Glaser K. The knowledge and attitudes of coronary heart disease prevention among middle and older aged people in a community in Taipei. Lay people's knowledge and attitudes of CHD prevention. Taiwan Geriat Gerontol 2009;4(4):251-262.

45. Devanathan R, Esterhuizen TM, Govender RD. Overweight and obesity amongst Black women in Durban, KwaZulu-Natal: A 'disease' of perception in an area of high HIV prevalence. Afr J Prim Health Care Fam Med 2013;5(1):1-7. https://doi.org/10.4102/phcfm.v5i1.450

46. Puoane T, Fourie JM, Shapiro M, Rosling L, Tshaka N. Obesity 'Big is beautiful' - an exploration with urban black community health workers in a South African township. S Afr J Clin Nutr 2005;18(1):6-15

47. Greenland S, Senn S, Rothman KJ, et al. Statistical tests, $p$-values, confidence intervals, and power: A guide to misinterpretations. Eur J Epidemiol 2016;31(4):337-350. https://doi.org/10.1007/s10654016-0149-3

Accepted 26 April 2017. 